\title{
Pengembangan Home Industri Bawang Merah Goreng Di Kelurahan Mlatiharo Kecamatan Semarang Timur
}

\author{
Tri Rinawati ${ }^{1}$, Rita Meiriyanti ${ }^{2}$, Tri Endang Yani $^{3}$ \\ 1,2,3 Universitas Semarang, Indonesia \\ Email: rinaoshin@gmail.com
}

\begin{abstract}
ABSTRAK
Masyarakat sebenarnya memiliki banyak potensi baik dilihat dari sumber sumber daya alam maupun dari sumber sosial budayanya. Masyarakat memiliki kekuatan yang bila digali dan disalurkan akan menjadi energi yang besar untuk membangun. Didalam pemberdayaan masyarakat yang penting adalah bagaimana menduduki masyarakat pada posisi pelaku pembangunan yang aktif, bukan penerima pasif, konsep gerakan pemberdayaan masyarakat mengutamakan inisiatif dan kreasi masyarakat dengan strategi pokok pemberian kekuatan kepada masyarakat. Masyarakat harus diberdayakan agar masyarakat mampu mengenali kebutuhan-kebutuhannya, merumuskan rencana-rencananya serta melaksanakan pembangunan secara mandiri dan swadaya. Permasalahan utama pengusaha industri rumahan produk bawang merah goreng di wilayah Kelurahan Mlatiharjo Kecamatan Semarang Timur ini tentang kualitas produk yang belum maksimal, kurangnya pemahaman tentang aspek pasar dan pemasaran.Kegiatan pengabdian ini dilakukan dengan pendekatan penyuluhan, pelatihan dan pendampingan para pelaku usaha industri rumahan di wilayah Kelurahan Mlatiharjo Kecamatan Semarang Timur, evaluasi hasil, serta metode sharing sebagai media pemecahan masalah. Pelaksanaan kegiatan Pengabdian Kepada Masyarakat di Kelurahan Mlatiharjo Kecamatan Semarang Timur telah terlaksana. Kegiatan yang dilakukan yaitu memberikan pemahaman tentang pentingnya perbaikan kualitas produk, aspek pasar dan pemasaran melalui kegiatan penyuluhan; melakukan diskusi mengenai kegiatan pengabdian tentang hal-hal yang terkait dengan kualitas produk, aspek pasar dan pemasaran; melatih cara menggunakan alat perajang baik manual maupun mesin serta cara menggunakan mesin spinner atau mesin peniris; kegiatan pendampingan melakukan proses produksi, penggunaan alat, pengemasan dan pelabelan; kegiatan evaluasi setelah kegiatan pengabdian.
\end{abstract}

Kata kunci: Industri Bawang Merah Goreng, Skala Rumah Tangga

\section{Development Of Onion Home Industries In The Mlatiharo Kelurahan, Kecamatan Semarang Timur}

\begin{abstract}
The community actually has a lot of potential both seen from the source of natural resources as well as from the cultural social source. Society has the power that when excavated and channeled will be a great energy to build. In the important community empowerment is how to occupy the community in the position of active development actors, not passive recipients, the concept of community empowerment movement prioritizes the initiative and creation of society with the main strategy of giving power to the community. The community must be empowered so that the community can recognize its needs, formulate its plans and carry out development independently and self-reliant. The main problem of the entrepreneur of home industry of fried onion product in Mlatiharjo Subdistrict of East Semarang Subdistrict is about product quality that has not maximal, lack of understanding about market and marketing aspect.This devotional activity is carried out by extension, training and mentoring approach for home industry in Mlatiharjo Sub-district, East Semarang District, evaluation of result, and sharing method as problem solving media.Implementation of Community Service activity in Mlatiharjo Sub-district, East Semarang Sub-district has been done. Activities undertaken include providing an understanding of the importance of improving product quality, market and marketing aspects through extension activities; conducting discussions on the activities of dedication on matters relating to product quality, market and marketing aspects; trained how to use chopper tools both manual and machine and how to use spinner or slicer machine; mentoring activities undertake production process, tool usage, packaging and labeling; evaluation activities after dedication activities.
\end{abstract}

Keywords: Fried Onion Industry, Household Scale 


\section{PENDAHULUAN \\ Analisis Situasi}

Gerakan pemberdayaan pada hakekatnya merupakan suatu instrumen perubahan sosial berencana yang berfungsi dan bertanggung jawab untuk mengatasi masalah-masalah kemiskinan dan implikasinya serta meningkatkan tarap kesejahteraan masyarakat pada umumnya. Gerakan pemberdayaan masyarakat dikembangkan oleh masyarakat agar dapat mengatasi masalah sosialnya yang tujuan utamanya meningkatkan kesejahteraan perorangan dan masyarakat secara keseluruhan.

Masyarakat sebenarnya memiliki banyak potensi baik dilihat dari sumber sumber daya alam maupun dari sumber sumber sosial dan budayanya. Masyarakat memiliki kekuatan yang bila digali dan disalurkan akan menjadi energi yang besar untuk membangun. Didalam pemberdayaan masyarakat yang penting adalah bagaimana menduduki masyarakat pada posisi pelaku pembangunan yang aktif, bukan penerima pasif, konsep gerakan pemberdayaan masyarakat mengutamakan inisiatif dan kreasi masyarakat dengan strategi pokok pemberian kekuatan kepada masyarakat. Masyarakat harus diberdayakan agar masyarakat mampu mengenali kebutuhan-kebutuhannya, merumuskan rencana-rencananya serta melaksanakan pembangunan secara mandiri dan swadaya.

Di Kelurahan Mlatiharjo Kecamatan Semarang Timur terdapat sentra industri pengolahan bawang merah goreng tetapi masih dalam skala rumah tangga. Pada awalnya yang melakukan bisnis tersebut hanya satu orang saja, yang lain sebagai karyawan yang mengupas dan mengiris bawang merah, karena dirasa lebih menguntungkan melakukan bisnis sendiri maka bertambahlah jumlah ibu-ibu yang melakukan bisnis tersebut. Pelaku usaha bawang merah goreng yang terdapat di wilayah kelurahan Mlatiharjo kecamatan Semarang Timur terdiri dari 12 orang antara lain Ibu

Narti, Ibu Saimah, Ibu Endang, Ibu Mamik, Ibu Mulyono, Ibu Suyatmi, Ibu Sulkan, Ibu Giyono, Ibu Dwi, Ibu Suliyah, Ibu Mujiyah dan Ibu Budi Irawan.

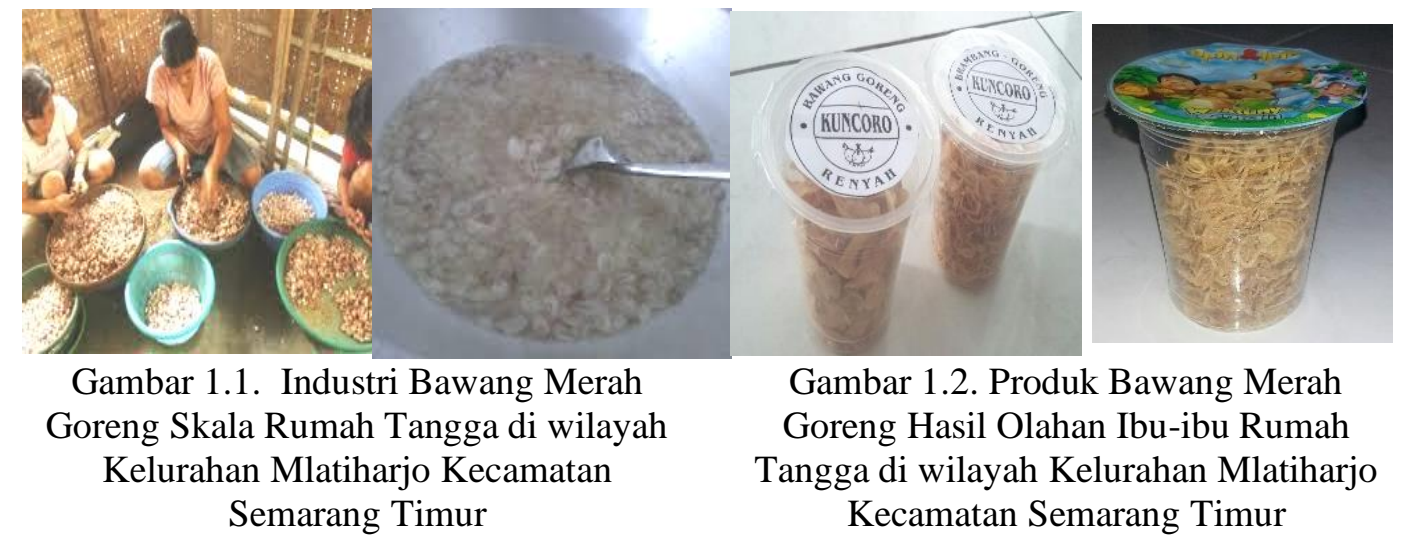

Permasalahan utama pengusaha industri rumahan produk bawang merah goreng di wilayah kelurahan Mlatiharjo kecamatan Semarang Timur adalah kualitas produk belum maksimal dalam hal inovatif dan pengembangan produk. Secara khusus masalah pengusaha kecil tersebut adalah produk bawang merah goreng yang dihasilkan kurang renyah dan menarik dalam hal bentuk irisan bawang merah goreng, rasa dan kerenyahan. Pengembangan produk tersebut sangat penting untuk menarik minat pembeli, terlebih usaha ini diharapkan dapat meningkatkan penghasilan keluarga dan dapat menjadi produk olahan sentra industri di wilayah Kelurahan Mlatiharjo Kecamatan Semarang Timur. Pemasaran produk baru di sekitar pasar tradisional, belum merambah ke pasar modern.

Berdasarkan analisis situasi yang telah dijelaskan, maka kualitas produk bawang merah goreng di wilayah Kelurahan Mlatiharjo Kecamatan Semarang Timur dapat dimaksimalkan melalui penyuluhan dan pelatihan pengembangan produk, aspek pasar dan pemasaran sehingga 
para pengusaha kecil tersebut dapat menentukan strategi pemasaran dan produksi guna pengembangan usaha mereka selanjutnya.

\section{Permasalahan Mitra}

Permasalahan utama pengusaha industri rumahan produk bawang merah goreng di wilayah Kelurahan Mlatiharjo Kecamatan Semarang Timur ini adalah : (1) Kualitas produk bawang merah goreng belum maksimal meliputi belum menampilkan karakteristik produk terkait kualitas rasa dan kerenyahan, belum ada kesesuaian dengan standar yang telah ditentukan oleh Badan Pengawas Obat dan Makanan (BPOM), dalam hal ini ijin Pangan Industri Rumah Tangga (PIRT), ketahanan produk belum diketahui karena belum mencantumkan tanggal produksi terkait dengan masa kadaluwarsa, estetika produk belum sesuai seperti tampilan kemasan bawang merah goreng yang kurang menarik, beberapa pelaku usaha belum memberikan kesan kualitas produk yaitu merek. (2) Aspek pasar meliputi pelaku usaha belum mengetahui berapa jumlah pasar potensial yang tersedia, pelaku usaha belum mengetahui berapa jumlah pangsa pasar yang tersedia dari seluruh pasar potensial. (3) Aspek Pemasaran yaitu pelaku usaha belum mengetahui tentang pendistribusian produk, penetapan harga dan pengawasan produk dan pasar untuk kelangsungan hidup usaha..

\section{TARGET DAN LUARAN}

Solusi yang ditawarkan diantaranya memperbaiki kualitas produk bawang merah goreng meliputi kualitas rasa dan kerenyahan, perijinan (BPOM dan PIRT), mencantumkan tanggal produksi, memperbaiki tampilan kemasan, emberikan merek; memberikan penyuluhan tentang pemahaman pasar potensial dan pangsa pasar yang tersedia dari seluruh pasar potensial; emberikan penyuluhan tentang pendistribusian produk, penetapan harga dan pengawasan produk dan pasar untuk kelangsungan hidup usaha.

\section{Target Luaran}

\section{Target}

Target program pengabdian kepada masyarakat ini adalah pengusaha kecil industri rumahan produk bawang merah goreng mampu menerapkan manajemen produksi yang baik dan mampu menerapkan strategi pemasaran dalam menjual produknya melalui bauran pemasaran dengan baik, dengan sasaran adalah pelaku usaha bawang merah goreng dalam hal ini ibu-ibu rumah rangga di wilayah Kelurahan Mlatiharjo Kecamatan Semarang Timur.

\section{Luaran}

Luaran yang dihasilkan dari program ini adalah peningkatan kemampuan manajemen produksi dan manajemen pemasaran.

\section{METODE}

\section{Metode Pelaksanaan Program}

Kegiatan dilakukan dengan pendekatan penyuluhan, pelatihan dan pendampingan para pelaku usaha industri rumahan di wilayah Kelurahan Mlatiharjo Kecamatan Semarang Timur. Pelaksanaan kegiatan pemberdayaan dilakukan melalui langkah-langkah sebagai berikut : (1) Analisis situasi lokasi untuk mengetahui potensi dan kebutuhan masyarakat sasaran dan ketersediaan bawang merah sebagai bahan baku. (2) Sosialisasi program dengan para pelaku usaha sasaran untuk menyamakan persepsi mengenai program pemberdayaan. (3) Penyuluhan dan pelatihan tentang kualitas produk, aspek pasar dan aspek pemasaran. (4) Pembentukan kelompok usaha bawang merah goreng (paguyuban). (5) Pengujian hasil praktek pengolahan bawang merah meliputi perbaikan kualitas produk, pemahaman aspek pasar dan aspek pemasaran. (6) Evaluasi hasil pengujian aspek pasar, aspek pemasaran serta penentuan prioritas pengembangan hasil olahan bawang merah yang paling menguntungkan dan diminati oleh konsumen. Hasil pelaksanaan program dievaluasi melalui pengamatan secara langsung, penyebaran kuesioner tentang manfaat program kepada mitra peserta program pengabdian 
masyarakat, kemungkinan pengembangannya secara komersial untuk meningkatkan pendapatan keluarga. (7) Pengembangan home industry dengan mendampingi para pelaku usaha sasaran: a. Kualitas produk; b. Aspek pasar; c. Aspek pemasaran.
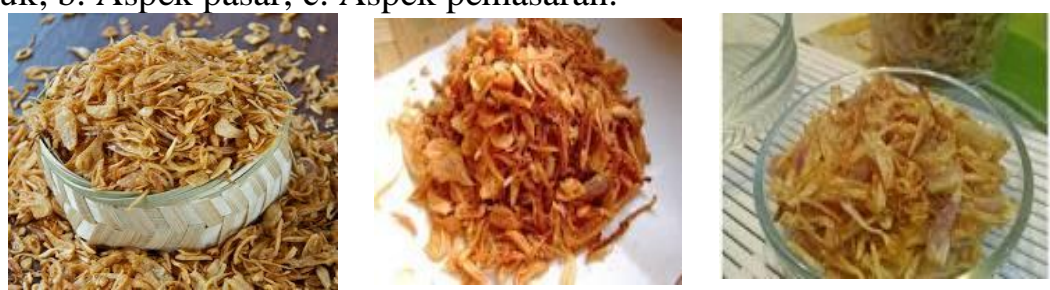

Gambar 3.1. Contoh Hasil Produksi Bawang Merah Goreng Yang Menarik

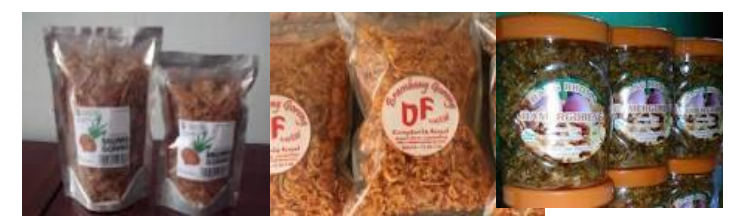

Gambar 3.2. Contoh Kemasan Bawang Merah Goreng Yang Menarik

(8) Selanjutnya metode sharing dan diskusi digunakan untuk memberikan kesempatan kepada peserta penyuluhan untuk bertanya dan mencari jalan pemecahan permasalahan yang dihadapi peserta penyuluhan.

\section{HASIL DAN PEMBAHASAN \\ Hasil}

Pelaksanaan kegiatan pengabdian oleh Tim Pengabdian Masyarakat Fakultas Ekonomi dilaksanakan selama 1 (satu) hari yaitu pada hari Kamis, tanggal 11 Januari 2018 di wilayah RT 002 RW 002 Kelurahan Mlatiharjo Kecamatan Semarang Timur, dihadiri oleh 10 (sebelas) peserta yang terdiri dari pengusaha bawang merah goreng skala rumah tangga.

Pelaksanaan Kegiatan Pengabdian dapat diuraikan sebagai berikut :

1. Pelatihan dan Penyuluhan mengenai kualitas produk, aspek pasar dan aspek pemasaran.

2. Pelatihan mengenai proses persiapan produksi, proses produksi hingga pengemasan dan pelabelan.

\section{Luaran Yang Dicapai}

Pelaksanaan kegiatan Pengabdian Kepada Masyarakat di Kelurahan Mlatiharjo Kecamatan Semarang Timur telah terlaksana. Dalam hal ini telah dilakukan kegiatan sebagai berikut : (1) Memberikan pemahaman tentang pentingnya perbaikan kualitas produk, aspek pasar dan pemasaran melalui kegiatan penyuluhan. (2) Melakukan diskusi mengenai kegiatan pengabdian tentang hal-hal yang terkait dengan kualitas produk, aspek pasar dan pemasaran. (3) Melatih cara menggunakan alat perajang baik manual maupun mesin serta cara menggunakan mesin spinner atau mesin peniris. (4) Kegiatan pendampingan melakukan proses produksi, penggunaan alat, pengemasan dan pelabelan. (50 Kegiatan evaluasi setelah kegiatan pengabdian.kualitas produk melalui produksi dan kemasan. 

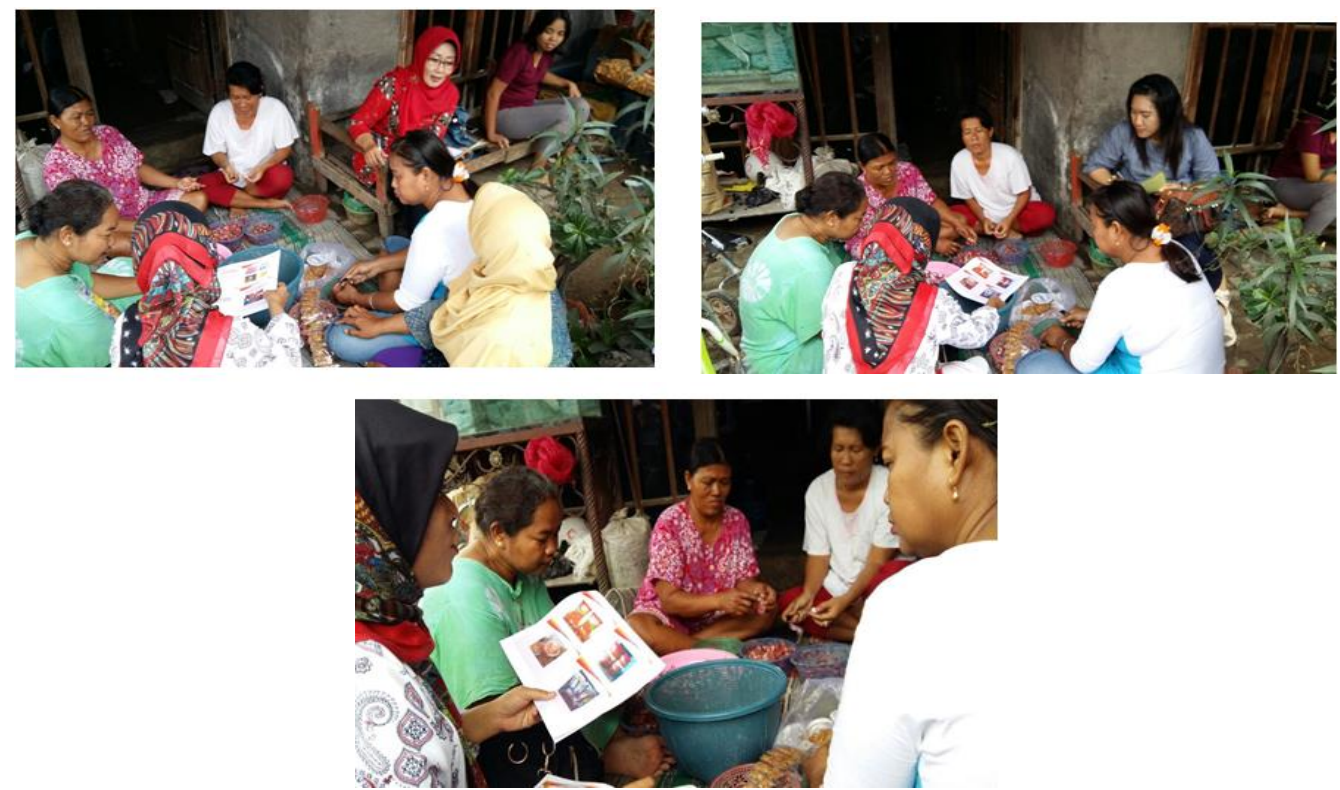

Gambar 5.16. Kegiatan diskusi antara Tim Pengabdian dengan Pelaku Usaha Bawang Merah Goreng

\section{SIMPULAN}

Kegiatan pengabdian oleh tim dosen Universitas Semarang yang dilaksanakan pada tanggal 11 Januari 2018 di wilayah RT 002 RW 002 Kelurahan Mlatiharjo Kecamatan Semarang Timur dihadiri oleh 10 peserta yang terdiri dari pelaku usaha bawang merah goreng. Peserta sangat antusias untuk mengikuti penyuluhan dan pelatihan hal ini terlihat dari jumlah kehadiran, dimana semua peserta yang hadir dan menjadi target penyuluhan dan pelatihan mengikuti acara tersebut dari awal sampai akhir serta sangat antusias dalam sesi tanya jawab, diskusi ataupun sharing. Pelaksanaan kegiatan Pengabdian Kepada Masyarakat di Kelurahan Mlatiharjo Kecamatan Semarang Timur telah terlaksana. Kegiatan yang dilakukan yaitu memberikan pemahaman tentang pentingnya perbaikan kualitas produk, aspek pasar dan pemasaran melalui kegiatan penyuluhan; melakukan diskusi mengenai kegiatan pengabdian tentang hal-hal yang terkait dengan kualitas produk, aspek pasar dan pemasaran; melatih cara menggunakan alat perajang baik manual maupun mesin serta cara menggunakan mesin spinner atau mesin peniris; kegiatan pendampingan melakukan proses produksi, penggunaan alat, pengemasan dan pelabelan; kegiatan evaluasi setelah kegiatan pengabdian.

\section{DAFTAR PUSTAKA}

Direktorat Pembinaan Kursus dan Kelembagaan. (2010). Manajemen Usaha Kecil, Direktorat Jendral Pendidikan Non Formal dan Informal, Kementerian Pendidikan Nasional, Jakarta

Kotler Philip dkk (2012). Manajemen Pemasaran Perspektif Asia, Buku Dua, Edisi Pertama, Andy, Yogyakarta.

Swastha, Basu dan Irawan (2005), Manajemen Pemasaran Modern, Edisi Kedua, Cetakan Kesebelas, Liberty Offset, Yogyakarta.

Kotler. (2008). Manajemen Pemasaran II. Jakarta: Erlangga

Kotler, Philip dan Gary Armstrong. (2003). Dasar-Dasar Pemasaran. Edisi Kesembilan. Jilid1 